BMJ Open Sport \& Exercise Medicine

\title{
Systematic development of a tennis injury prevention programme
}

Haiko I M F L Pas, ${ }^{1,2,3}$ Stefan Bodde, ${ }^{4}$ Gino M M J Kerkhoffs, ${ }^{1,2,3}$ Babette Pluim, ${ }^{4}$ Ivo J H Tiemessen, ${ }^{5}$ Johannes L Tol, ${ }^{2,6}$ Evert Verhagen, ${ }^{3,7,8,9}$

Vincent Gouttebarge $e^{1,2,3,8,10}$

To cite: Pas HIMFL, Bodde S, Kerkhoffs GMMJ, et al. Systematic development of a tennis injury prevention programme. BMJ Open Sport \& Exercise Medicine 2018:4:e000350. doi:10.1136/ bmjsem-2018-000350

- Additional material is published online only. To view please visit the journal online (http://dx.doi.org/10.1136/ bmjsem-2018-000350).

Accepted 9 April 2018

\section{Check for updates}

For numbered affiliations see end of article.

Correspondence to Dr Vincent Gouttebarge; v.gouttebarge@amc.uva.nl

\section{ABSTRACT}

Introduction Despite an injury incidence of up to 3.0/1000 hours of play, there are no published tennis injury prevention programmes. This article aims to describe the developmental process of TennisReady, an e-health tennisspecific injury programme for adult recreational tennis players.

Five-step approach A bottom-up, five-step approach was used with the Knowledge Transfer Scheme as a guideline. During the first step, a problem statement among targeted users was carried out. 475 (partially) completed surveys and group interviews $(n=8)$ revealed a preference for an app-based prevention intervention of 10-15 min. As a second step, a systematic review was performed to identify prevention strategies in tennis. None were found. In step 3, during two expert group meetings $(n=18)$, the findings of the first two steps were discussed and goals were formulated. Relevant and potential exercises for the programme were discussed. A subgroup of a total of six physical therapists, physicians and trainers developed the content of the programme in step 4. Step 5 included an evaluation of the exercises in 33 recreational tennis players. Participants evaluated the exercises during training sessions with trainers involved in the programme's development or their colleagues. Participants evaluated the programme through standardised surveys or group interviews. Based on this evaluation, the programme was adjusted by altering exercises and frequencies, and it was evaluated in a second target group $(n=27)$. The second evaluation did not result in any major changes to the final prevention programme.

Conclusion Through a five-step approach guided by the Knowledge Transfer Scheme, we developed an e-health tennis-specific prevention programme for adult tennis players. This 10 min intervention will require testing in a randomised controlled setting.

\section{INTRODUCTION}

Exercise-based injury prevention strategies in sports have been frequently evaluated. ${ }^{1}$ A meta-analysis of 36 randomised controlled trials has shown that most of these interventions are effective in reducing the number of injuries. ${ }^{1}$ The majority of trials have been conducted in team sports, such as basketball, volleyball, football (soccer) and tackle collision ball sports (eg, rugby union). ${ }^{12}$

\section{What is already known on this subject?}

Tennis is one of the most practised individual sports with approximately 75 million people practising tennis worldwide.

- While playing tennis has health benefits for the cardiovascular system and for decreasing allcause mortality, tennis is also associated with musculoskeletal injuries.

What this study adds?

Using a new development protocol, a tennis-specific e-health intervention was developed in order to reduce or prevent the occurrence of musculoskeletal injuries.

- The intervention, named TennisReady, consists of two warm-up programmes (on-court and offcourt) lasting approximately 10 min and based on cardiovascular, neuromuscular and tennis-specific exercises that should be performed twice weekly for a period of 12 weeks.

- Information and instructions (text and videos) about TennisReady are available in an app for smartphones/ tablets, providing tennis players and coaches every week with a new warm-up programme that shows progressive increments in terms of intensity, frequency, duration and/or complexity.

For individual sports, the literature is limited to running athletes. Only three randomised controlled trials for exercise-based prevention in runners have been published, which all showed no significant reduction in injury rates. ${ }^{3-5}$ Given the global individual sports participation exceeds team participation, ${ }^{6}$ the lack of evidence-based prevention intervention is a call for action.

Tennis is one of the most practised individual sports in the world. ${ }^{6}$ Estimates show that approximately 75 million people practise tennis worldwide. ${ }^{7}$ Playing tennis has proven cardiovascular health benefits and is even associated with decreased all-cause mortality. ${ }^{89}$ The downside is the injury rate of up to $3.0 / 1000$ hours of tennis. ${ }^{10}$ 
These injuries have an important (economic) impact. A recent Dutch report ${ }^{11}$ showed that $43 \%$ of the injuries among tennis players were treated (para)medically, leading to an emergency room treatment cost of $€ 3.6$ million. ${ }^{11}$ Indirect costs due to loss of work were estimated at $€ 8.3$ million. When taking into account that approximately 800000 people play tennis in the Netherlands, ${ }^{12}$ the worldwide impact of tennis-related injuries can be considered significant.

Therefore, using a new development protocol, an e-health intervention was developed for recreational tennis players in the Netherlands. Previously, intervention mapping (IM) $)^{13} 14$ was commonly applied ${ }^{15-18}$ for the development of this type of interventions. However, a novel programme, the Knowledge Transfer Scheme (KTS), ${ }^{19}$ was recently published. The KTS is a practical five-step tool for developing intervention strategies in sports. ${ }^{19}$ The fundament of the KTS is the direct translation of evidence into practice. Prospected users are involved throughout the KTS process; however, the resulting intervention is based on findings from literature reviews. ${ }^{19}$ The KTS can thus lead to a more evidencebased and user-friendly product or programme.

The aim is to describe the systematic development of a tennis-specific, exercise-based e-health intervention using the KTS. To our knowledge, we are the first to report the formal application of the KTS in practice.

\section{Development of the intervention}

A bottom-up, systematic five-step approach with guidance of the $\mathrm{KTS}^{19}$ was used to develop a tennis-specific injury prevention programme. This bottom-up approach implied that tennis players, trainers and other stakeholders contributed to the development of the programme. The KTS consists of five steps: (1) problem statement, which seeks to review the magnitude of the problem (epidemiological, economical and social); (2) evidence synthesis and description, which aims to review the scientific evidence that is already available in order to estimate the gain from the aimed intervention; (3) knowledge transfer group meetings with stakeholders from the target group and researchers with relevant expertise-this group discusses the findings of the first two steps and makes recommendations for the next step; (4) product development, during which the 'product', in this case the prevention programme, is fully developed; and (5) finally, during evaluation, the programme is tested for effectiveness and is implemented. As we will illustrate in this article, we deviated somewhat from the formal KTS. Figure 1 shows the process steps that were used.

\section{Steps 1 and 2: problem statement and evidence synthesis}

The aims of the first two steps were (1) to assess the needs and knowledge of tennis players, trainers and other stakeholders within tennis about injury prevention, and (2) to evaluate whether there was any prior high-quality scientific evidence for preventive measures for tennis-related

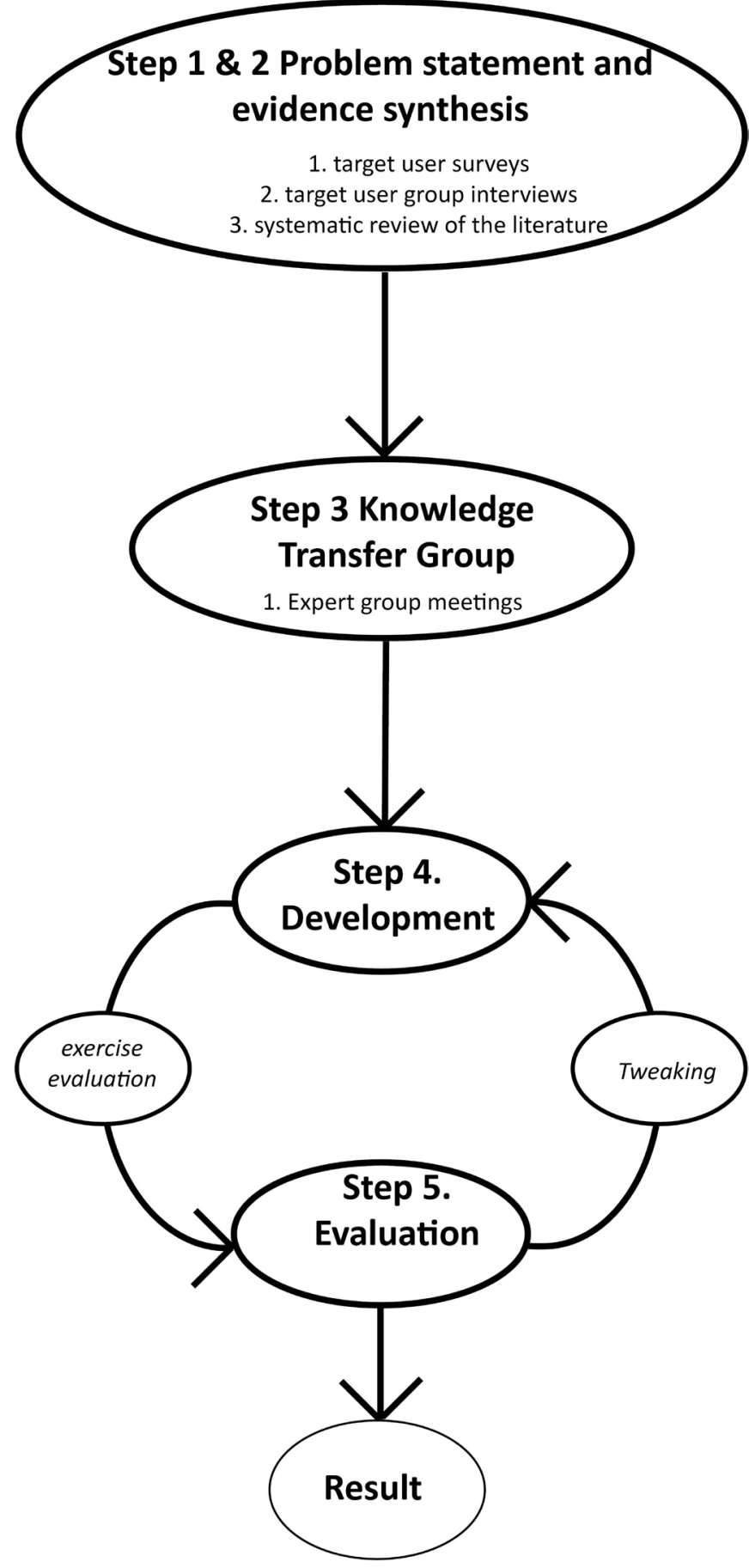

Figure 1 Flow chart of the development process.

injuries. During step 1, we evaluated the knowledge and needs of adult tennis players.

\section{Step 1: needs assessment}

Anonymous electronic surveys (in Dutch) were digitally distributed by the Royal Netherlands Lawn Tennis Association (KNLTB) in their monthly newsletter among 49.608 (105 emails bounced) tennis players and coaches (end of 2015). The surveys (see online supplementary appendix 1) included 11 structured questions on injury prevention, current injury prevention practice, and players' and coaches' needs. The questions enquired 
475 surveys were (partially) returned

$96 \%$ were tennis players.

$\square \quad 62 \%$ of participants felt that their club paid no attention to injury prevention.

$\square \quad 53 \%$ believed they had insufficient knowledge about injury prevention.

$\square \quad 45 \%$ indicated not spending any time on injury prevention,

$\square \quad 75 \%$ answered twice or more when asked how often they would want to perform exercises

$\square$ A maximum of 10 minutes was considered acceptable by $44 \%$ of participants, $48 \%$ would have accepted more.

\section{$42 \%$ believed that exercises should be performed on-court.}

\section{$54 \%$ felt that an app would be most suited to transfer the intervention.}

Figure 2 Summary of the online surveys.

if there was sufficient motivation for an intervention and the preferred format.

Four hundred and seventy-five (partially) completed surveys were returned (96.2\% tennis players). Figure 2 summarises the findings. Participants reported a lack of information on injury prevention $(53 \%)$ and a lack of time spent on injury prevention $(45 \%)$, and $44 \%$ preferred the intervention to last for a maximum of 10 min. The key results from the group interviews confirmed the survey results: (1) strong preference for preventive exercises and (2) preference for an e-health/app-based intervention.

Two semistructured group interviews were held (May 2016) with 8-12 players, trainers, (para-)medics, policy makers, and representatives of tennis clubs and a national tennis association. Each focus group interview was led by one author (VG) and took on average 2 hours. These interviews assessed the knowledge on tennis injuries, potential preventative measures, and dissemination of information on prevention to the players and trainers.

\section{Step 2: evidence synthesis}

A systematic literature review ${ }^{20}$ was conducted. The full methodology was published in PROSPERO (ID CRD42015026297). No randomised controlled trials on injury prevention strategies in tennis were identified. ${ }^{20}$

\section{Step 3: knowledge transfer group (expert group meetings)}

Guided by the KTS, ${ }^{19}$ a multidisciplinary expert group (EG) was assembled and two meetings were held. The EG consisted of 18 participants, who were selected on their expertise and role in tennis and injury prevention: six tennis players/coaches/policy makers (all occupied multiple functions), three physical trainers, four (sports) physical therapists, three (sports medicine) physicians and two expert consultants. The EG was informed at the start of the first meeting about the results of the review, surveys and interviews. During the two meetings of 2 hours, the content of the proposed intervention programme was discussed.

The EG stated that a behaviour change was indicated, as within current practice, adult tennis players frequently refrain from warm-up and/or strengthening exercises. This was formulated as an important behavioural change goal. With regard to the programme's content and form, the majority preferred the following:

1. Usage of elastic bands: Although within the group the usage of elastic bands was debated, the majority of experts emphasised its additional value and free availability was advised.

2. An on-court and off-court programme: The majority of the experts strongly recommended on-court and off-court programmes because of (1) the minimum required frequency for training effect and (2) optimising compliance for players.

3. Based on epidemiological data, ${ }^{10}{ }^{21}$ the EG agreed that exercises focusing on the ankle, knee, elbow and shoulder injury prevention should be key: Potentially (combination of) useful exercises were selected from existing exercise-based injury programmes or formulated by EG members. ${ }^{22-24}$ Non-practical exercise forms (eg, floor exercises) were marked as not useful.

4. A smartphone app with instruction videos: As the number of people with smartphones is very high, ${ }^{25}$ this was considered as an adequate and accessible 
medium. A smartphone app could easily hold all the information and instruction videos. It also matched the findings of the surveys among tennis players and other stakeholders. It was therefore agreed by the experts that the programme would be fitted for a smartphone app.

\section{Step 4: content development}

All information gathered in the previous two steps was synthesised and translated for the intervention's development. Two work sessions were held with the development group including six experts in the field of tennis and injury prevention ((sports) physical therapists, strength and conditioning trainers, (sports) physicians, injury prevention experts). Each work session took 4 hours and was led by one author (VG).

The intervention (named TennisReady) consisted of two programmes. The development group members preferred to include exercises from existing effective injury prevention programmes. ${ }^{22-24}$ In the absence of an effective exercise form, an alternative exercise was developed using a combination of one or more existing exercises. The on-court programme consisted of cardiovascular, neuromuscular and tennis-specific exercises. The off-court programme contained neuromuscular exercises only. To accommodate for improvement of strength and coordination, the programmes' intensity was increased weekly by increasing the load, number of repetitions and/or content (complexity). For both programmes, exercises with and without elastic bands were available.

\section{Step 5: evaluation}

The KTS recommends that an evaluation follows the RE-AIM (Reach, Effectiveness, Adoption, Implementation, Maintenance) framework. ${ }^{26}$ However, due to the lack of other tennis injury prevention programmes, we adjusted this step into a qualitative evaluation of the exercises and a 'tweaking' session, which allowed us to alter the content of the programme prior to its completion.

\section{Exercise evaluation}

The exercises were evaluated among 33 recreational tennis players (male and female; age range: 32-80 years) of different levels. The players were asked to evaluate the exercises after having performed them during their training sessions with affiliated trainers or their colleagues. The evaluation was aimed at assessing whether the exercises were feasible and could be completed within $10 \mathrm{~min}$. The evaluation was performed at two different tennis clubs and supervised by two of the authors (HIMFLP, SB). Players were asked to assess their feasibility in terms of (1) usefulness, (2) practical use, (3) instructions, (4) duration and (5) difficulty/ complexity. These aspects were assessed during standardised individual and group interviews and scored on a standard form (from 0 to 10 , with ' 0 ' as extreme unfavourable value and ' 10 ' as extreme favourable value).
The participants rated the cardiovascular warm-up exercises of the on-court programme as useful and easy to use (with approximately $70 \%$ scoring $\geq 8 / 10$ for all areas). The elder participants indicated that knee raise exercises were hard to perform. During group evaluations, participants emphasised the importance of the cardiovascular exercises. Higher level players (playing level $3-5 / 10, n=5)$ rated the cardiovascular exercises as easy, and some indicated that more arm swing exercises might be useful.

For the neuromuscular exercises, a large heterogeneity in responses was obtained. Overall, lower extremity exercises such as the (semi) squat, lunge and skate jumps were rated as useful by the majority ( $>70 \%$ giving a score of $\geq 7 / 10$ for all areas). Coordination exercises were considered as difficult and scores for these exercises decreased overall.

Upper extremity exercises included static stretching exercises. The majority still rated them as useful and easy ( $>80 \%$ rating them $\geq 7 / 10$ for all areas), but the exercises were replaced by (eccentric) loading exercises due to a lack of evidence. ${ }^{27}$

The tennis-specific exercises (mini-tennis-based drills and sprinting drills) were considered very useful. Over $80 \%$ scored the mini-tennis drills $\geq 8 / 10$ for all areas and $80 \%$ scored the sprint drills $\geq 7 / 10$ for all areas.

A subgroup ( $\mathrm{n}=16$, age range $32-62)$ tested the off-court knee and shoulder exercises with and without elastic band (high band resistance). Seven out of the 16 (44\%) participants indicated that the resistance of the provided bands was too high. The shoulder exercises scored relatively low on the usefulness domain, with six players rating the usefulness section $\leq 6(0-10)$. The knee exercises scored better, with $12(75 \%)$ players rating them as useful $(\geq 7 / 10)$ and $13(81 \%)$ as easy to perform $(\geq 7 / 10)$.

\section{Tweaking}

The exercise evaluation was summarised in a report. Based on this report, a follow-up meeting was organised with the members of the development group (step 4). Several exercises were altered. The adjusted exercises were re-evaluated in a new group of 27 adult tennis players (male and female; age range 18-65 years). None of the players found any of the exercises too difficult and only one player indicated that one exercise (cross body racket swing) was less useful (score 5/10). Minor adjustments were recommended by the players on the number of repetitions or duration of several exercises. These results were equally reported to the development group (step 4) and resulted in minor changes, which were not re-evaluated.

The final version of the e-health (app-based) TennisReady programme consisted of on-court and off-court components, to be conducted twice weekly for a period of 12 weeks. A 12-week period was chosen because the two competitive seasons (spring and fall) both last approximately 3 months in the Netherlands and because tennis lessons are usually offered to players in sets of 
Table 1 Sample routine of the TennisReady on-court programme (in this case: week 6 with elastic band option)

Cardiovascular: circuit run: performed over the width of a tennis court (ie, 8-10 m), time: 2 min

\begin{tabular}{|ll}
\hline Dribbling & 2 reps \\
\hline Skipping with arm swings & 2 reps \\
\hline Sidesteps & 2 reps \\
\hline Dribbelling with arm swings & 2 reps \\
\hline Line run & 2 reps \\
\hline Neuromuscular time: 5 min & \\
\hline Half T with band & $12 / a r m$ \\
\hline W with band & 14 reps \\
\hline $\begin{array}{l}\text { PNF (proprioceptive neuromuscular } \\
\text { facilitation)hip-to-shoulder }\end{array}$ & 12 reps \\
\hline Leg swing & $5 / l e g$ \\
\hline Diver with band & $3 \times 10$ s/leg \\
\hline Monster walk with band around & Knot at $10 \mathrm{~cm}$ from \\
knees & end \\
\hline Tennis-specific time: 3 min & 2 reps \\
\hline $\begin{array}{l}\text { Service line T, return forwards } \\
\text { Mini-tennis within two service areas, }\end{array}$ & Minimum 2 min \\
\hline slice only &
\end{tabular}

8-12 weeks. Each on-court and off-court programme lasted approximately $10 \mathrm{~min}$ and included cardiovascular, neuromuscular and tennis-specific exercises. A total of 4 different cardiovascular routines, 52 different exercises focusing on balance, strength and range of motion, and 4 tennis-specific circuits and 4 tennis-specific warm-up games were included. Each on-court and off-court routine began at week 1 and increased in intensity by increasing the number of repetitions or the duration of an exercise or by changing the exercise to a more complex form. This was done so on a weekly basis. Information and instructions (with instruction videos) of the exercises and routines were available in an app for smartphones/tablets (table 1, figure 3).

\section{DISCUSSION}

Using a bottom-up, KTS-guided, five-step process, we developed a tennis-specific app-based tennis injury prevention programme. Using input from target users and experts, both on-court and off-court exercise routines were developed and evaluated. After a tweaking and a re-evaluation of the exercises, a final product was made available through a smartphone/table app.

Exercise-based prevention has been extensively studied in the literature and is effective in reducing the number of injuries. ${ }^{128}$ Unfortunately, all proven interventions have only been studied in team sports settings. ${ }^{12} 28$ Randomised controlled trials evaluating exercised-based prevention in individual sports were performed in runners but none was found to be effective. ${ }^{3-5}$ One of these trials used static stretching pre-exercise and postexercise. ${ }^{3}$ Another one used a graded exercise principle, ${ }^{4}$ and lastly one trial used a preseason conditioning scheme. ${ }^{5}$ Ongoing insight has taught us that static stretching is not effective, ${ }^{27}$ explaining the results of van Mechelen et al. ${ }^{3}$ During the other two trials, no attention to inseason prevention was given, ${ }^{45}$ which seems important for exercise-based injury prevention. ${ }^{128}$

One more vitally important difference that exists between individual and team sports trials is the coach. Team sports exercise-based interventions are most often coach-delivered interventions, ${ }^{2329-35}$ meaning there is adequate supervision to the intervention. ${ }^{30}{ }^{36}$ This may be important for compliance, which has been linked to the success of exercise-based interventions. ${ }^{36}{ }^{37}$ We feel that for individual sports, coachbased interventions are still preferred, but in daily practice are less feasible as most individuals train individually. An app-based platform may be the way into individual athletes' training sessions. Whether this will indeed increase compliance has to be evaluated.

Our methodology for developing our e-health intervention was guided by the KTS. ${ }^{19}$ The KTS was introduced in 2014 and was designed to translate evidence into practice in sports medicine. To our knowledge, we are the first to report its use for the development of a sport-specific prevention intervention. Previously, sports interventions were developed using IM. ${ }^{15-18}$ Although the KTS leans closely on IM, there are important differences, such as the direct translation of evidence into practice in the KTS. ${ }^{19}$ The KTS uses target users throughout the entire development process, whereas IM only uses them for the needs assessment. ${ }^{131419}$ As the KTS aims at translating evidence into practice, it focuses less on investigating behavioural change determinants and developing new strategies. ${ }^{19}$

Because of its practicality and use of target users throughout the process, we used the KTS as a guideline. This did however pose problems. First, no evidence was available for tennis-specific injury prevention, which forced us to rely on (the limited) evidence from team sports. This implied that we were forced to develop a new product. Although most experts involved in this process were active tennis players, we did not formally invite a sample of tennis players with no other affiliations or expertise to join in on the EG sessions. We did reintroduce them in the process when we needed feedback on the first version of our programme.

Another major difference between the formal KTS and our approach was the use of a small development group. The KTS suggests that content development is also the responsibility of the knowledge transfer group $(\mathrm{EG})^{19}$; however, we felt this would be an inefficient way to create new content. We therefore chose to use volunteers with sufficient expertise to develop the programme's content.

Lastly, the fifth step of the KTS, ${ }^{19}$ 'evaluation', was modified because no formal evaluation according to the RE-AIM framework was possible. ${ }^{26}$ We did perform an evaluation of the exercises with our target users and this resulted in an additional step we named 'Tweaking'. This step leans closely to the IM step 4, where refinement of 


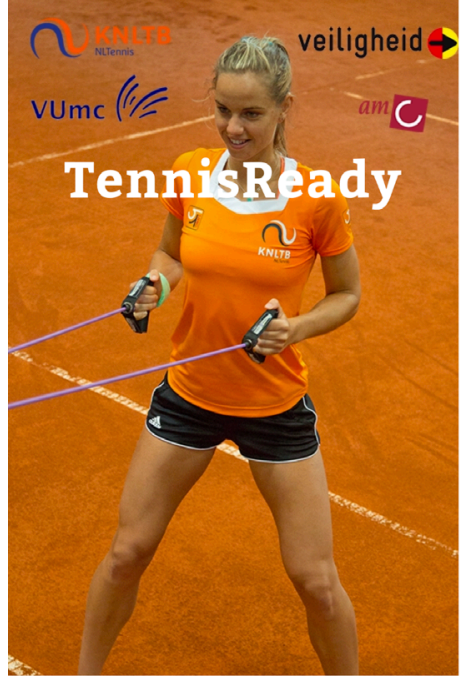

$\bigcap_{\substack{\text { Nangs } \\ K N G}}^{K L T}$

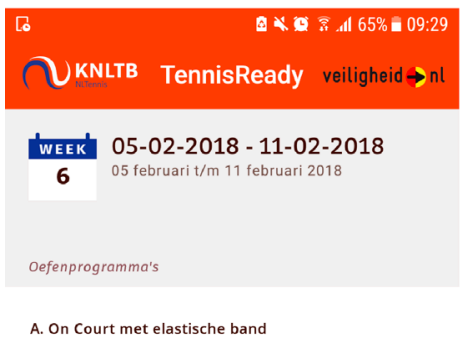

B. On Court zonder elastische band

c. Off Court met elastische band

D. Off Court zonder elastische band

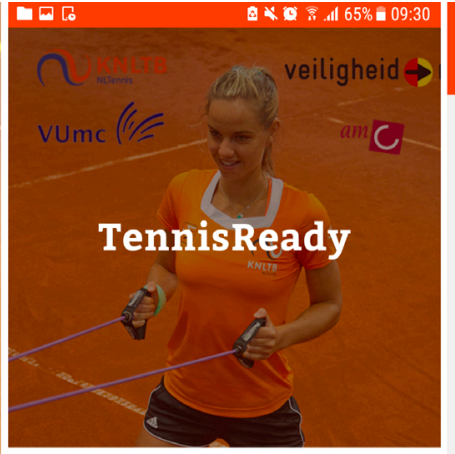

Emailadres

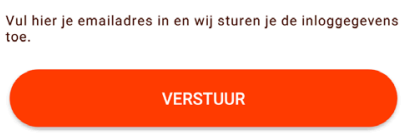

@KNLTB

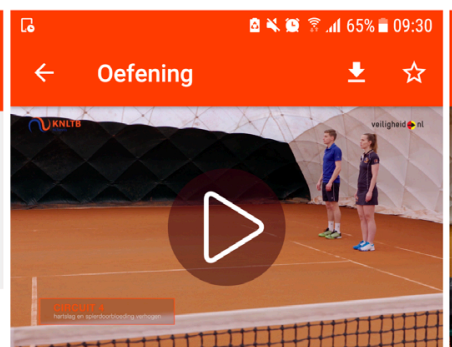

Circuit 4

Oefening

Het doel van het circuit is de hartslag omhoog te krijgen en de doorbloeding van de spieren te verbeteren waardoor je beter de komende inspanning aankunt en mogelijk iets minder spierblessures oploopt.

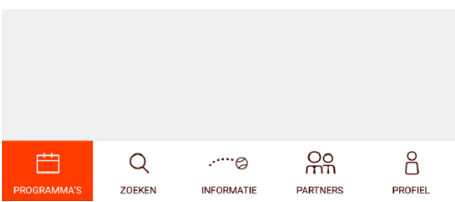

Doel

Het doel van het circuit is de hartslag omhoog te kriigen en de doorbloeding van de spieren te verbeteren waardoor je beter de komende inspanning aankunt en mogelijk iets minder
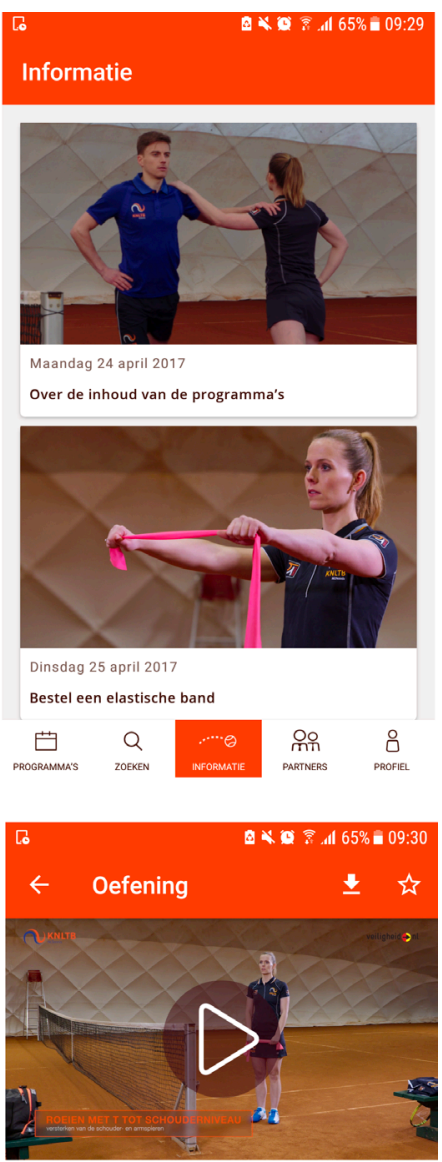

Roeien met $\mathrm{T}$ tot schouderniveau Oefening

Het versterken van de schouderspieren met als doel het voorkomen van schouder- en mogelijk ook elleboogblessures.

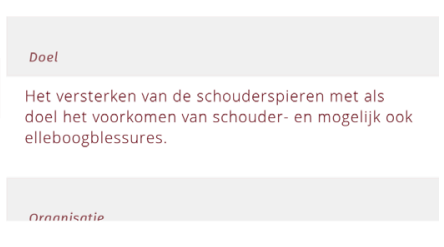

Figure 3 TennisReady: an intervention for tennis players available through smartphone/tablet.

the programme is addressed. ${ }^{14}$ As shown in figure 1 , it allows the developers to go back one step and adjust the programme, which was the case during our process.

Despite the deviations of the formal KTS, we believe that we are able to present a systematically developed e-health prevention intervention for adult tennis players. Our deviations were made out of practical considerations and out of necessity (eg, modification of step 5). Formal evaluation according to the RE-AIM framework ${ }^{26}$ has been planned after a large-scale effectiveness test in a randomised controlled trial setting (Dutch trial registration number NTR6443).

\section{CONCLUSION}

Using a systematic approach guided by the KTS, we developed a tennis-specific, app-based tennis injury prevention programme. Its effectiveness will be tested in a randomised controlled trial.

\section{Author affiliations}

${ }^{1}$ Department of Orthopaedic Surgery, Academic Medical Center, Amsterdam Movement Sciences, University of Amsterdam, Amsterdam, The Netherlands ${ }^{2}$ Academic Center for Evidence-Based Sports Medicine (ACES), Amsterdam, The Netherlands

${ }^{3}$ AMC/VUmc IOC Research Center, Amsterdam Collaboration on Health \& Safety in Sports (ACHSS), Amsterdam, The Netherlands

${ }^{4}$ Department of Sports Medicine, Royal Netherlands Lawn Tennis Association, Amersfoort, The Netherlands

${ }^{5}$ Mobilito Sport, Amsterdam, The Netherlands

${ }^{6}$ Aspetar Orthopaedic and Sports Medicine Hospital, Doha, Qatar

${ }^{7}$ Department of Public and Occupational Health, Amsterdam Movement Sciences, VU University Medical Center Amsterdam, Amsterdam, The Netherlands

${ }^{8}$ Division of Exercise Science and Sports Medicine, University of Cape Town, Cape Town, South Africa 
${ }^{9}$ Australian Centre for Research into Injury in Sport and its Prevention (ACRISP), Federation University Australia, Ballarat, Victoria, Australia

${ }^{10}$ Dutch Consumer Safety Institute, Amsterdam, The Netherlands

Acknowledgements We greatly thank all tennis experts involved in the development of the intervention: Honzik Pavel, Maarten te Veldhuis, Aldo Hoekstra, Hanna Steggink, Claire Verheul, Miguel Janssen, Leonne Heffels, Annelies Geel, Eric Broere, Mark de Jong, Loes Bons, Dorien Evenaars and Victor Zuidema.

Contributors All authors were responsible for the conceptualisation of the study. HIMFLP was responsible for drafting the manuscript, while all other authors were responsible for the critical review of the manuscript. All authors read and approved the final manuscript.

Funding The study was partly funded by the Dutch Organisation for Health Research and Development (ZonMw).

Competing interests None declared.

Patient consent Not required.

Provenance and peer review Not commissioned; externally peer reviewed.

Open Access This is an Open Access article distributed in accordance with the Creative Commons Attribution Non Commercial (CC BY-NC 4.0) license, which permits others to distribute, remix, adapt, build upon this work non-commercially, and license their derivative works on different terms, provided the original work is properly cited and the use is non-commercial. See: http://creativecommons.org/ licenses/by-nc/4.0/

(C) Article author(s) (or their employer(s) unless otherwise stated in the text of the article) 2018. All rights reserved. No commercial use is permitted unless otherwise expressly granted.

\section{REFERENCES}

1. Leppänen M, Aaltonen S, Parkkari J, et al. Interventions to prevent sports related injuries: a systematic review and meta-analysis of randomised controlled trials. Sports Med 2014:44:473-86.

2. Vriend I, Gouttebarge V, Finch CF, et al. Intervention Strategies Used in Sport Injury Prevention Studies: A Systematic Review Identifying Studies Applying the Haddon Matrix. Sports Med 2017;47:2027-43.

3. van Mechelen W, Hlobil $\mathrm{H}$, Kemper HC, et al. Prevention of running injuries by warm-up, cool-down, and stretching exercises. Am J Sports Med 1993;21:711-19.

4. Buist I, Bredeweg SW, van Mechelen W, et al. No effect of a graded training program on the number of running-related injuries in novice runners: a randomized controlled trial. Am J Sports Med 2008;36:33-9.

5. Bredeweg SW, Zijlstra S, Bessem B, et al. The effectiveness of a preconditioning programme on preventing running-related injuries in novice runners: a randomised controlled trial. Br J Sports Med 2012;46:865-70

6. Hulteen RM, Smith JJ, Morgan PJ, et al. Global participation in sport and leisure-time physical activities: A systematic review and metaanalysis. Prev Med 2017;95:14-25.

7. Pluim BM, Miller S, Dines D, et al. Sport science and medicine in tennis. Br J Sports Med 2007;41:703-4.

8. Pluim BM, Staal JB, Marks BL, et al. Health benefits of tennis. Br J Sports Med 2007:41:760-8

9. Oja P, Kelly P, Pedisic Z, et al. Associations of specific types of sports and exercise with all-cause and cardiovascular-disease mortality: a cohort study of 80306 British adults. Br J Sports Med 2017;51:812-17.

10. Pluim BM, Staal JB, Windler GE, et al. Tennis injuries: occurrence, aetiology, and prevention. Br J Sports Med 2006;40:415-23.

11. Stam C, Tennisblessures HV. Blessurecijfers 2014. 2014. https:// www.veiligheid.nl/.ibmmodres/domino/OpenAttachment/veiligheid/ website.nsf/FD998F1284E5DA19C1257FE9003E932B/asset/Cijf ersfactsheet\%20Tennis\%202014.pdf.

12. Stam C, Tennisblessures VH. Blessurecijfers 2014. 2014. www. veiligheid.nl.

13. Bartholomew LK, Parcel G, Kok G. Intervention mapping: designing theory-and evidence-based health promotion programs. Mayfield: Mountain View, 2001
14. Eldredge LKB, Markham CM, Kok G. Planning health promotion programs: an intervention mapping approach. USA: John Wiley \& Sons, 2016

15. Collard DC, Chinapaw MJ, van Mechelen W, et al. Design of the iPlay study: systematic development of a physical activity injury prevention programme for primary school children. Sports Med 2009;39:889-901.

16. Donaldson A, Poulos RG. Planning the diffusion of a neck-injury prevention programme among community rugby union coaches. $\mathrm{Br}$ J Sports Med 2014:48:151-9.

17. Viljoen W, Patricios J. BokSmart - implementing a National Rugby Safety Programme. Br J Sports Med 2012;46:692-3.

18. Gouttebarge V, van Sluis $\mathrm{M}$, Verhagen $\mathrm{E}$, et al. The prevention of musculoskeletal injuries in volleyball: the systematic development of an intervention and its feasibility. Inj Epidemiol 2017;4:25.

19. Verhagen $E$, Voogt $N$, Bruinsma A, et al. A knowledge transfer scheme to bridge the gap between science and practice: an integration of existing research frameworks into a tool for practice. Br J Sports Med 2014;48:698-701.

20. Oosterhoff J, Gouttebarge V, Moen MH. Tennis injuries: risk factors and prevention strategies.

21. Dines JS, Bedi A, Williams PN, et al. Tennis injuries: epidemiology, pathophysiology, and treatment. J Am Acad Orthop Surg 2015;23:181-9.

22. F-marc.com. Fifa $11+$ a complete warm-up program to prevent injuries, manual. 2016. http://f-marc.com/11plus/manual/ (accessed 09 Sep 2016).

23. Andersson SH, Bahr R, Clarsen B, et al. Preventing overuse shoulder injuries among throwing athletes: a cluster-randomised controlled trial in 660 elite handball players. Br J Sports Med 2017;51:1073-80.

24. Hupperets MD, Verhagen EA, van Mechelen W. Effect of unsupervised home based proprioceptive training on recurrences of ankle sprain: randomised controlled trial. BMJ 2009;339:b2684.

25. Number of smartphone users worldwide: eMarketer 2016. 2017. https://www.statista.com/statistics/330695/number-of-smartphoneusers-worldwide/ (accessed 07 Nov 2017).

26. Glasgow RE, Vogt TM, Boles SM. Evaluating the public health impact of health promotion interventions: the RE-AIM framework. Am J Public Health 1999;89:1322-7.

27. Small K, Mc Naughton L, Matthews M. A systematic review into the efficacy of static stretching as part of a warm-up for the prevention of exercise-related injury. Res Sports Med 2008;16:213-31.

28. Sewry N, Verhagen E, Lambert M, et al. Exercise-Based Interventions for Injury Prevention in Tackle Collision Ball Sports: A Systematic Review. Sports Med 2017;47:1847-57.

29. Longo UG, Loppini M, Berton A, et al. The FIFA 11+ program is effective in preventing injuries in elite male basketbal players: a cluster randomized controlled trial. Am J Sports Med 2012;40:996-1005

30. Pfile KR, Curioz B. Coach-led prevention programs are effective in reducing anterior cruciate ligament injury risk in female athletes: A number-needed-to-treat analysis. Scand J Med Sci Sports 2017:27:1950-8.

31. Barengo NC, Meneses-Echávez JF, Ramírez-Vélez R, et al. The impact of the FIFA 11+ training program on injury prevention in football players: a systematic review. Int J Environ Res Public Health 2014;11(11(11)):11986-2000.

32. Hammes D, Aus der Fünten K, Kaiser S, et al. Injury prevention in male veteran football players - a randomised controlled trial using "FIFA 11+". J Sports Sci 2015;33:873-81.

33. Owoeye OB, Akinbo SR, Tella BA, et al. Efficacy of the FIFA 11+ Warm-Up Programme in Male Youth Football: A Cluster Randomised Controlled Trial. J Sports Sci Med 2014;13:321-8.

34. Silvers-Granelli $\mathrm{H}$, Mandelbaum B, Adeniji O, et al. Efficacy of the FIFA $11+$ Injury Prevention Program in the Collegiate Male Soccer Player. Am J Sports Med 2015;43:2628-37.

35. Soligard T, Myklebust G, Steffen K, et al. Comprehensive warm-up programme to prevent injuries in young female footballers: cluster randomised controlled trial. BMJ 2008;337:a2469.

36. van Reijen M, Vriend I, van Mechelen W, et al. Compliance with Sport Injury Prevention Interventions in Randomised Controlled Trials: A Systematic Review. Sports Med 2016;46:1125-39.

37. Goode AP, Reiman MP, Harris L, et al. Eccentric training for prevention of hamstring injuries may depend on intervention compliance: a systematic review and meta-analysis. $\mathrm{Br} J$ Sports Med 2015;49:349-56. 